\title{
Ser e Não-Ser na ontologia de Sartre: a constituição do Para-si e a emergência do sentido
}

\section{Being and Non-Being in the ontology of Sartre: For the constitution of the For-Itself and the emergence of the sense}

\section{HELEN ALINE DOS SANTOS MANHÃES ${ }^{1}$}

Resumo: O artigo aborda, a partir do contexto da reflexão sartriana, a problemática da constituição do Para-Si e a emergência do sentido. Busca-se, então, compreender como a reflexão aparece como retomada da vivência irrefletida, que a recupera e posiciona como seu objeto. Assim, o irrefletido traduz uma primazia ontológica em relação a uma consciência tomada como instância última irredutível, conforme a tese canônica da redução fenomenológica husserliana.

Palavras-chave: Sartre. Consciência. Irrefletido. Ser. Nada.

Abstract: The article discusses, from the context of Sartre's thought, the problem of the constitution of the For-Itself and the emergence of meaning. Search is then understood as the reflection appears as resumption of unreflective experience, that retrieves and positions as their object. Thus, the thoughtless translates an ontological primacy in relation to a consciousness taken as irreducible ultimately, as the canonical theory of Husserl's phenomenological reduction.

Keywords: Sartre. Consciousness. Unreflective. Being. Nothingness.

Na introdução da obra O Ser e o Nada, Sartre delineia sua proposta a partir da crítica que faz especialmente à filosofia de Husserl. Opondo-se a este, Sartre rejeita tanto o idealismo quanto o realismo, partindo em busca duma compreensão ontológica do real que não fundamente o ser do fenômeno na consciência, ou seja, que não defina o ser do fenômeno como 'ser é ser percebido', e, por outro lado, que não separe mundo e consciência enquanto duas entidades extrínsecas e independentes, unidas por uma relação também externa. A pretensão de Sartre, já de partida, é

1 Mestranda em Filosofia na UFSC. Ex-bolsista do PET-Filosofia/UNIOESTE (2010-2012). Endereço eletrônico: helen_asm@hotmail.com 


\section{HELEN ALINE DOS SANTOS MANHÃES}

desenvolver uma compreensão do ser que permita dois aspectos: um ser transfenomenal do fenômeno e um ser transfenomenal da consciência, de tal modo que ambos estejam relacionados originariamente, vinculados dum modo essencial sem que, no entanto, o ser de um se reduza ao ser do outro. Consciência e fenômeno são as duas regiões do "ser em geral", que designa tudo aquilo que de algum modo é. Estas duas esferas do ser, entretanto, existem sob um modo radicalmente distinto, e é por aí que deve começar um estudo da consciência.

Sartre parte da noção de fenômeno enquanto aquilo que aparece, aquilo que se manifesta. $\mathrm{O}$ existente é tal qual se mostra, não havendo por detrás dele um ser ou uma essência oculta que deveria, num processo de análise, ser encontrada. $\mathrm{O}$ fenômeno não mostra nem esconde seu ser e, no entanto, o indica em cada uma de suas partes. Isto significa, seguindo Husserl, que o objeto é a série de suas aparições e a razão mesma desta série. Mas isto, reduzir o objeto ao seu aparecer, não basta para Sartre. Há que se elucidar o sentido do ser transfenomenal do fenômeno, aquilo que sustenta a aparição do que aparece e, no entanto, não se dá diretamente numa intuição.

A definição de fenômeno enquanto 'aquilo que aparece' pressupõe alguém a quem aparecer, e este é o segundo modo de ser enquanto estrutura do real: a consciência. Esta possui um modo de existência radicalmente distinto do fenômeno. Ela define-se, em negativo, como não sendo uma coisa, uma substância, uma matéria onde se poderiam imprimir representações. A consciência é um vazio de consistência própria, assemelha-se, por analogia, mais a um movimento do que a uma coisa, e existe somente em correlação a um objeto. $\mathrm{O}$ conceito-chave para entendê-la reside na ideia de intencionalidade, definida assim: "toda consciência é consciência de alguma coisa." (SARTRE, 2009, p. 22) Deve-se entender esta proposição em seu sentido mais profundo, que é um princípio da consciência, e não mera tautologia. Significa que o modo próprio da consciência existir é referindo-se permanentemente - porque originariamente - a um objeto que ela não é. A consciência surge como posicionamento do objeto transcendente e só pode surgir nesta relação: visando, posicionando aquilo que ela não é.

A elucidação da consciência, de sua constituição e de seus 
princípios deve passar pela diferenciação das duas regiões de ser na medida em que se implicam mutuamente, descrevendo a relação fundamental que faz com que consciência e mundo surjam já ligados. Sartre afirma a importância de tomar esta unidade sintética, que chama, apropriando-se do conceito de Heidegger, homemno-mundo, pois estes dois termos só poderiam ser analisados separadamente por meio de um processo de abstração, visto que se dão à intuição sempre como uma totalidade indissolúvel. "A consciência e o mundo são dados de uma só vez: por essência exterior à consciência, o mundo é, por essência, relativo a ela" (SARTRE, 2005, p. 56).

Ultrapassando o fenômeno rumo ao seu ser, que não pode ser captado numa intuição, mas que é indicado em todo fenômeno, há que se descobrir o sentido deste ser, ou seja, aquilo do ser que é acessível à consciência, o modo como ele se indica através do fenômeno, o que se pode dizer dele ainda que não se o apreenda de modo adequado. E este modo de ser, como uma primeira região do ser em geral, é chamado Ser-Em-Si. Uma descrição ainda provisória do ser do fenômeno extrai dele três características que esgotam tudo aquilo que se pode saber acerca dele: o ser é; o ser é Em-si; o ser Em-si é o que é. Tais afirmações podem parecer redundantes e até mesmo simples derivações do princípio de identidade. No entanto, se analisadas mais a fundo, revelam o modo de ser do ser do fenômeno. "O ser é Em-si" expressa a adesão total que o Emsi tem com si mesmo, como está empastado de si, que nele não há distância alguma que permita relação com si mesmo ou com qualquer outro objeto exterior - ele desconhece a alteridade-, assim como está além de toda afirmação ou negação, pois igualmente deveria distanciar-se de um ser para afirmar ou negar algo acerca dele. "O ser Em-si é o que é": longe de se tratar do princípio de identidade (a base incondicional de todo juízo analítico e, como princípio, válido universalmente), trata-se duma região de ser e, portanto, dum princípio sintético. Designa a opacidade do Emsi. "O ser Em-si é": "significa que o ser não pode ser derivado do possível, nem reduzido ao necessário.” (SARTRE, 2009, p. 39). Não é necessário porque a necessidade pertence às proposições ideais e não à ordem dos existentes; não é possível porque a possibilidade provém do Para-si, ou seja, de outra região de ser. Quer-se dizer com isso que o ser é supérfluo. "Incriado, sem razão de ser, sem 
relação alguma com outro ser, o ser-Em-si é supérfluo para toda a eternidade" (SARTRE, 2009, p. 40).

Eis as três determinações possíveis do Em-si, que serão retomadas e levadas em conta na elucidação ontológica da consciência, visto que seu ser é descrito intimamente ligado ao ser do fenômeno.

O propósito desta primeira abordagem visa à elucidação da consciência em seus contornos fundamentais. Sendo radicalmente distinta do modo de ser do fenômeno, exige o estudo próprio de seu ser.

Pode-se concordar conosco, todavia, que o percipi remete a um ser que escapa às leis da aparição, desde que esse ser transfenomenal seja o ser do sujeito. Assim, o percipi remeteria ao percipiens - o conhecido ao conhecimento e este ao ser cognoscente enquanto é, não enquanto é conhecido, quer dizer, à consciência [...]. Pois a lei de ser do sujeito cognoscente é ser-consciente. A consciência não é um modo particular de conhecimento, chamado sentido interno ou conhecimento de si: é a dimensão de ser transfenomenal do sujeito (SARTRE, 2009, p. 21-22).

A investigação do ser do fenômeno, enquanto condição de desvelar e fundamento permanente do que aparece, conduziu ao ser daquele que conhece, visto que seu ser é o que escapa às condições da aparição fenomênica, pois não depende de uma relação de conhecimento para ser apreendido. O ser do sujeito cognoscente, a consciência, existe sob uma condição que, como afirma Sartre, é necessária e suficiente: ser consciente de si. Ao contrário do que se poderia pensar, no entanto, não se trata de uma consciência reflexiva que conhece a si própria, numa relação de sujeito-objeto, de posicionamento. O que ocorre na percepção, por exemplo, que é um modo da consciência direcionar seu olhar ao mundo e esgotar-se nele, é percepção do objeto transcendente, mas, ao mesmo tempo, há consciência da percepção do objeto. Eis o cogito pré-reflexivo.

Dito de modo simples, a lei da consciência é existir consciente $(\mathrm{de})^{2}$ si em todo e qualquer ato seu. Tal afirmação, apesar de simples, 2 Os parênteses indicam que tal consciência não é posicional, que se trata duma consciência imediata de si e não da consciência tética, reflexiva. Por questões 
é de tal modo radical que se pode afirmar que não há vida para a consciência a não ser enquanto consciência de existir, consciência de suas vivências. Uma dor, por exemplo, não existe salvo sob o modo de consciência (de) dor. Sem reduzir a dor a uma qualidade da consciência e, por outro lado, sem considerar a dor como uma potência, um atributo existente por si ao qual viesse se acrescentar depois a qualidade de consciente, a consciência (de) dor é o único modo possível de existência para uma dor. "Esta consciência (de) si não deve ser considerada uma nova consciência, mas o único modo de existência possível para uma consciência de alguma coisa" (SARTRE, 2009, p. 25).

A lei de existência da consciência é ser consciente de si de modo imediato, numa relação de ser e não de conhecimento. Assim, Sartre estabelece o irrefletido como anterior e originário em relação à reflexão. $\mathrm{O}$ cogito pré-reflexivo

[...] aparece como sendo a necessidade primordial que tem a consciência irrefletida de ser vista por si mesma; comporta originariamente, portanto, esse caráter dirimente de existir para um testemunho, embora esse testemunho para o qual a consciência existe seja ela mesma (SARTRE, 2009, p. 123).

A própria noção de intencionalidade, que estabelece o modo de ser da consciência como consciência de algo que não ela, revela a primazia da 'vida natural', espontânea da consciência, na qual há consciência posicional do objeto transcendente e consciência não posicional de si. A reflexão aparece como retomada da vivência irrefletida, que a recupera e posiciona como seu objeto. Antes de existir voltada para si mesma, a consciência é consciente (de) si através de sua relação com o mundo. Esta anterioridade do irrefletido traduz sua primazia ontológica, isto é, ser consciente (de) si é a lei da consciência, seu modo fundamental de existir.

A consciência é assim definida: ela é o que não é e não é o que é. Aparentemente uma contradição. Ao se considerar o ser Em-si, que é plena positividade e adere a si totalmente, há que, no entanto, se notar que há um tipo de realidade que foge ao ser e não pode provir dele: o não-ser. Não se pode derivar o não-ser do ser:

gramaticais, pela dificuldade em dizer tal modo de consciência, os parênteses são utilizados. 


\section{HELEN ALINE DOS SANTOS MANHÃES}

ser só pode gerar ser, pois é pleno de si mesmo. O não-ser não pode, no entanto, gerar a si próprio, pois, não sendo, não tem poder para extrair de si a força necessária para nadificar-se. Ao contrário, como afirma Sartre, o nada é nadificado. Assim, é necessário que haja um ser capaz de sustentar o não-ser - ou nada - no ser, um ser que deve relacionar-se com o nada de dentro, de modo fundamental, caso contrário, se lhe fosse atribuída esta relação de fora, este nada lhe seria exterior e necessitaria novamente de outro ser para sustentálo. Este ser que traz o nada ao ser e o sustenta em seu coração é o homem, o Para-si.

Sartre se utiliza o que chama de negatividades para mostrar que é o homem quem traz o nada ao mundo. Realidades como a negação, a interrogação (uma postura tão característica e comum do homem, presente nas vivências mais simples deste), a ausência apenas vêm ao mundo através da realidade humana e, enquanto negatividades, são fundamentadas no nada original que as possibilita. "A condição necessária para que seja possível dizer não é que o não-ser seja presença perpétua, em nós e fora de nós. É que o nada infeste o ser." (SARTRE, 2009, p. 52) É por que o homem carrega em seu âmago o não-ser que tais realidades negativas são possíveis, e não por que elas existem que podemos no nível da linguagem, dizer não, nada, ninguém.

Torna-se necessário interrogar o que deve ser a consciência, o homem em seu ser, para que sustente o nada.

Queremos definir o ser do homem na medida em que condiciona a aparição do nada, ser que nos apareceu como liberdade. [...]. A liberdade humana precede a essência do homem e torna-a possível: a essência do ser humano achase em suspenso na liberdade. Logo, aquilo que chamamos liberdade não pode se diferençar do ser da "realidade humana". O homem não é primeiro para ser livre depois: não há diferença entre o ser do homem e seu "ser-livre" (SARTRE, 2009, p. 68).

A liberdade é "descoberta" em O Ser e o Nada através das condutas negativas. Tais condutas, como a interrogação, exigem um recuo da consciência diante do ser que o coloque como que em suspensão, em estado neutro, que o posicione entre o ser e o não-ser. 
Isto significa que a consciência encontra-se fora do processo causal que determina o Em-si, pois, se não fosse assim, haveria apenas ser indefinidamente. Tanto o distanciamento que a consciência assume mediante mundo como a quebra da relação causal dizem respeito à liberdade que rege a consciência.

Num sentido mais profundo, a liberdade insinua-se no seio da realidade humana como aquilo que a separa de si mesma. Se esta se encontra alheia à cadeia determinista das coisas, o que é que se insinua entre motivo e ato na vida da consciência? Nada pode determinar uma consciência, no sentido de gerar um novo estado a partir de um precedente. Através do fluxo temporal, a consciência se relaciona com seu passado e seu futuro sempre transpassada por um nada que a separa daquilo que foi e do que será. Sou o meu passado ao modo de não sê-lo, e nada me separa daquilo que fui. Do mesmo modo, sou o meu futuro à maneira de não sê-lo, e na estrita medida em que o que serei não é determinado pelo que sou agora.

Um ótimo exemplo da nadificação de meu ser-passado está na figura do jogador. Almejando livrar-se de seu vício, promete que amanhã não voltará a jogar e sente-se confiante em sua decisão. No dia seguinte verifica, no entanto, ao pé do tapete verde, que sua decisão já não tem força determinante sobre seu presente, por mais que busque na memória, revivendo o dia anterior, o que o fazia ter tanta pertinácia. A decisão confiante de antes e a falta de que se apoiar agora para mantê-la revela a falta de força causal entre meu presente e meu futuro, e isto por que um nada, intrínseco a meu modo de ser, faz com que minhas vivências não sejam originadas umas das outras entre si, como numa relação em cadeia de causa e efeito. $\mathrm{O}$ nada que desliza em meu seio torna meus possíveis meros possíveis, retirando de qualquer deles, mesmo após decisão acertada, a necessidade de se realizar.

Enquanto consciência, subjetividade, escapa-se às leis de determinação universal. Isto porque a consciência, no agir humano situado, constitui um conjunto de possíveis em relação ao porvir. Diferentemente dos objetos do mundo, que são regidos causalmente e podem ter suas trajetórias previstas e tomadas como certas, a consciência coloca suas próprias possibilidades e, o que é mais importante, está separada delas por um não-ser. Os possíveis 


\section{HELEN ALINE DOS SANTOS MANHÃES}

apelam, exigem sua realização em vistas de seu motivo - aquilo que seria sua causa se tivesse força para tal, se se tratasse dos objetos do mundo. No entanto, no caso da consciência, todo motivo é insuficientemente eficaz para determinar a efetivação de um possível. Assim, aparece à consciência sua indeterminação diante do futuro, e este é um aspecto de sua liberdade. Meu ser presente pode constituir motivos para meu ser futuro, mas não há entre eles força de determinação capaz de derivar o que serei do que sou, na mesma medida que o que fui já não é capaz de, por si só, sustentar meu ser presente - a força da decisão tomada no dia anterior está empalidecida pela minha liberdade.

Uma frase-ícone do existencialismo de Sartre sintetiza a relação essencial entre homem e liberdade: "A existência precede a essência." (SARTRE, 1973, p. 11). Novamente, homem e mundo existem sob leis distintas. Enquanto os objetos possuem essências definidas e estáticas, o homem primeiro surge no mundo, deparase consigo, e, a partir de suas escolhas e ações, constrói sua própria essência. A construção de si implica um vazio original, um nãoser primeiro que se tornará algo. A liberdade humana, existencial, como caráter íntimo de seu ser, dita que homem é, necessariamente, abertura diante de possíveis a partir dos quais se construirá. Dizer que o homem é, ontologicamente, livre é afirmar a necessidade que ele tem de perpetuamente escolher e, ao mesmo tempo, sua indeterminação, seu vazio original.

A liberdade ontológica pode ser apreendida de diferentes modos: ausência de determinação, necessidade perpétua de construir-se através de escolhas, falta de força causal entre motivo e ato, acontecimento absoluto e injustificável no ser. São diferentes maneiras de expressar a subjetividade da condição humana.

Como já dito a respeito do cogito pré-reflexivo, "a consciência de ser é o ser da consciência." (SARTRE, 2009, p. 75). Isto significa que, se a liberdade é o ser da consciência, este ser deve poder ser apreendido de algum modo pela consciência, ou então esta seria inconsciente de si - o que contraria seu próprio modo de ser. Sartre afirma ser na angústia que a consciência capta a si mesma em seu ser:

[...] é na angústia que o homem toma consciência de sua 
liberdade, ou, se se prefere, a angústia é o modo de ser da liberdade como consciência de ser; é na angústia que a liberdade está em seu ser colocando-se a si mesma em questão (SARTRE, 2009, p. 72).

A angústia é a apreensão reflexiva de si. Tanto a angústia frente ao passado quanto ao futuro revelam à consciência seu ser mais íntimo, que foi descrito anteriormente como nadificação do ser-Emsi, liberdade ontológica da consciência. Diz o filósofo: "A liberdade que se revela na angústia pode caracterizar-se pela existência do nada que se insinua entre os motivos e o ato." (SARTRE, 2009, p. 78).

\section{A constituição do Para-si}

O Para-si consiste numa descompressão de ser. É uma fissura que se abre no seio do Em-si. "Assim, o nada é esse buraco no ser, essa queda do Em-si rumo a si, pela qual se constitui o Para-si." (SARTRE, 2009, p. 127). A noção do si é o ponto central aqui. Ela denota relação do sujeito consigo mesmo. O si não é o sujeito, pois, se o fosse, constituiria uma identidade e recairia no Em-si. Ao mesmo tempo, não pode não sê-lo, pois é justamente o que o si indica: o sujeito. Escreve Sartre:

O si representa, portanto, uma distância ideal na imanência entre o sujeito e si mesmo, uma maneira de não ser sua própria coincidência, de escapar à identidade colocando-a como unidade [...] é o que chamamos presença a si. A lei de ser do Para-si, como fundamento ontológico da consciência, consiste em ser si mesmo sob a forma de presença a si (SARTRE, 2009, p. 125).

Toda presença a implica separação. O que significa que o Para-si é o ser que, separado de si mesmo, existe presente a si. O que é que separa o Para-si de si? Não pode haver a introdução dum elemento exterior: há uma unidade indissolúvel no seio do Para-si que mantém esta separação de si consigo mesmo. Caso contrário, ele se dissolveria em dois Em-si e recairia na plena positividade. O que o separa de si é o nada enquanto negação absoluta de 


\section{HELEN ALINE DOS SANTOS MANHÃES}

identidade, um nada que lhe é íntimo e que o motiva, em seu ser, a ser este desencontro perpétuo de si mesmo. Nota Sartre:

O ser da consciência, enquanto consciência, consiste em existir à distância de si como presença a si, e essa distância nula que o ser traz em seu ser é o Nada. Logo, para que exista um si, é preciso que a unidade deste ser comporte seu próprio nada como nadificação do idêntico. Pois o nada que desliza na consciência é o seu nada [...] o para-si é o ser que se determina a existir na medida em que não pode coincidir consigo mesmo (SARTRE, 2009, p. 127).

Ser o que não se é significa ser uma tentativa de ser si mesmo, mas uma tentativa eternamente frustrada, que não consegue se tornar efetiva em sua busca. É o desejo de tornar sua natureza a mesma do Em-Si, de fazer de si próprio uma plenitude que expulse qualquer lacuna de não-ser que, por sua vez, é o que permite a transcendência, é o que faz surgir a inadequação do homem consigo mesmo, que o transforma num desejo eternamente desejante e, como tal, falta perpétua. É a vontade de cessar a necessidade ontológica de ter que tender a algo. $\mathrm{O}$ homem nasce sob um destino contraditório: determinado a perseguir algo, está, por natureza, impedido de alcançar seu alvo. Ele é esta tendência inexorável, esta perseguição sem fim por completar-se, por existir de modo pleno através da coincidência consigo mesmo, sem querer, no entanto, lançar mão de sua condição de ser consciência. Tal é o sentido do fracasso primordial que Sartre atribui à condição humana.

Esta tendência inelutável do Para-si rumo a um si-mesmo ideal significa o movimento primordial de constituição do Para-si no seio do Em-Si. Afirma Sartre que a única possibilidade do ser é o Para-si. Sendo plenitude de ser e adesão perfeita a si, o EmSi existiria como uma massa indiferenciada de ser, alheio a si próprio. O único modo de escapar a esta indiferença do idêntico é degradar esta plenitude a partir de um movimento de negação desta positividade. Surge o desencontro que quebra a identidade e introduz a distância ideal, no seio do ser, de si consigo mesmo. Eis que surge o Para-si.

Assim se dá o processo de nadificação que ocorre no âmago do Para-si. Trata-se da degradação do Em-Si que, buscando 
fundamentar seu próprio ser, perde-se em Para-si, faz surgir o nãoser no mundo. É nesta medida que se pode afirmar que o Parasi é fundamento de seu próprio nada, porque é internamente que sustenta o nada de seu ser a partir da negação da identidade do Em-Si. Este Em-Si nadificado pelo Para-si, no entanto, não trata de uma massa de ser qualquer. O Em-Si que o Para-Si nega para surgir e se manter no ser o acompanha sempre e lhe é íntimo: trata-se precisamente do si.

Este processo de nadificação do ser exige que o Para-si exista sob o modo de falta de. Toda falta exige, necessariamente, três componentes: o que falta (ou o faltante), o que de fato há (o existente) e a totalidade rumo à qual se dirige o olhar que presencia uma falta e que constituiria uma existência plena (o faltado). "Todo faltante falta sempre a... para... E o que é dado na unidade de um surgimento primitivo é o para, concebido como não sendo ainda ou não sendo mais, ausência rumo à qual se transcende" (SARTRE, 2009, p. 138-139).

A totalidade que o Para-si persegue é justamente um simesmo ideal que seria o Para-si, ao modo do Em-Si, se pudesse coincidir consigo mesmo. "A relação negada na definição do Para-si [...] é uma relação dada como perpetuamente ausente entre o Parasi e si mesmo à maneira da identidade. [...] o que falta ao Para-si é o si - ou o si-mesmo como Em-si” (SARTRE, 2009, p. 139).

Eis o ser do valor. O Para-Si é quem mantém no ser a totalidade ideal que persegue constantemente. Sendo consciência, almeja a plenitude do Em-Si. Um sofrimento nunca é sofrido totalmente. Por ser consciente (de) si, perde sua pureza, sua densidade, nunca é sofrimento o bastante. Já se alojou aquela distância ideal que faz com que o si nunca esteja aqui, mas sempre em outro lugar. Sartre então descreve:

Cada lamento, cada fisionomia de quem sofre aspira a esculpir uma estátua Em-si do sofrimento. Mas esta estátua jamais existirá, salvo pelos outros e para os outros. [...] Por não ser o bastante, tagarela, mas seu ideal é o silêncio. $\mathrm{O}$ silêncio da estátua, do homem abatido que abaixa a cabeça e cobre o rosto sem dizer nada. Mas este homem silencioso só se cala para mim. Em si mesmo, tagarela inesgotavelmente, 
porque as palavras da linguagem interior são como esboços do "si" do sofrimento. Somente aos meus olhos é que ele está "esmagado" pelo sofrimento: em si mesmo, sentese responsável por esta dor que [...] está impregnada por perpétua ausência - a ausência do sofrimento imóvel e mudo que é o si, a totalidade concreta e inatingível do Para-si que sofre, o para da Realidade-humana sofredora (SARTRE, 2009, p. 143).

A consciência e o ser rumo ao qual ela se dirige surgem de uma só vez, pois se remetem mutuamente. A natureza desse ser é a mesma da consciência: ser consciente (de) si. O ideal do sofrimento, o sofrimento-si, que fornece sentido ao sofrimento enquanto falta, está no horizonte de meu sofrimento real; ele não é posicionado pela reflexão, antes, é o próprio modo de o sofrimento apreender-se como falta. E este "só pode ser sofrimento como consciência (de) não ser suficientemente sofrimento em presença deste sofrimento pleno e ausente." (SARTRE, 2009, p. 143). E é perpetuamente, em cada ato da vida da consciência, que ela se transcende em direção a essa totalidade irrealizável. Enquanto imanência absoluta da consciência, pois se encontra no âmago dela como seu sentido, torna-se transcendência absoluta, por sua natureza ideal e inalcançável.

É com estas bases que Sartre prepara o contexto que embasará sua ontologia. A purificação do campo transcendental, isto é, a elucidação da consciência enquanto absoluto de existência espontânea solicita agora que se explique como esta espontaneidade se relaciona com o mundo, tendo em vista que Sartre rejeita o idealismo transcendental de Husserl, mas também não admite o materialismo metafísico, o realismo ingênuo, enquanto postura filosófica.

O Ser e o Nada é o desdobramento desta descrição de como a consciência, em seu surgimento mesmo, faz surgir mundo: não do modo como o Ego transcendental constitui o mundo, pois, para Sartre, o ser se sustenta por si mesmo em sua permanência indeterminada e indiferente - o ser é. O que o Para-si faz é conferir sentido ao ser, a partir da nadificação de seu próprio ser, num movimento que persegue um ser ideal. A descompressão de ser que faz surgir o Para-si não é mais que um movimento incessante de 
busca pela coincidência de dois modos de ser, ser e não-ser, e o mundo aparece no meio dessa busca, quase como se se dissesse que o mundo serve de cenário a esta perseguição eterna e frustrada que é o homem. Sartre avalia que:

$\mathrm{O}$ Mundo não criou o $\mathrm{Eu}$ [Moi], o Eu [Moi] não criou o Mundo, eles são dois objectos para a consciência absoluta, impessoal, e é por ela que eles estão ligados. Esta consciência absoluta, quando é purificada do Eu, nada mais tem que seja característico de um sujeito, nem é também uma colecção de representações: ela é muito simplesmente condição primeira e uma fonte absoluta de existência (SARTRE, 1994, p. 83).

Crê-se que, em termos gerais, buscou-se, aqui, explicitar o que Sartre compreende como realidade humana sob uma determinação ontológica. Trata-se da consciência que sustenta um modo de ser que apreende a si mesmo como falta de ser através da negação fundamental de si, movimento nadificador que faz emergir do puro ser, as estruturas significantes que o homem chama 'mundo'.

\section{Referências bibliográficas}

SARTRE, Jean-Paul. A transcendência do ego. Tradução de Pedro M. S. Alves. Lisboa: Edições Colibri, 1994.

. O existencialismo é um humanismo. Tradução de Vergílio Ferreira. São Paulo: Abril Cultural, 1973.

. O ser e o nada: ensaio de ontologia fenomenológica.

Tradução de Paulo Perdigão. Petrópolis, RJ: Vozes, 2009.

. Uma ideia fundamental da fenomenologia de Husserl: a intencionalidade. In: Situações I: crítica literária. Tradução de Cristina Prado; prefácio de Bento Prado Jr. São Paulo: Cosac \& Naify, 2005. 